\title{
Distraction biases working memory for faces
}

\section{Remington Mallett ${ }^{1} \cdot$ Anurima Mummaneni $^{2} \cdot$ Jarrod A. Lewis-Peacock $^{1}$}

Published online: 6 January 2020

(C) The Psychonomic Society, Inc. 2020

\begin{abstract}
Working memory persists in the face of distraction, yet not without consequence. Previous research has shown that memory for low-level visual features is systematically influenced by the maintenance or presentation of a similar distractor stimulus. Responses are frequently biased in stimulus space towards a perceptual distractor, though this has yet to be determined for high-level stimuli. We investigated whether these influences are shared for complex visual stimuli such as faces. To quantify response accuracies for these stimuli, we used a delayed-estimation task with a computer-generated "face space" consisting of 80 faces that varied continuously as a function of age and sex. In a set of three experiments, we found that responses for a target face held in working memory were biased towards a distractor face presented during the maintenance period. The amount of response bias did not vary as a function of distance between target and distractor. Our data suggest that, similar to low-level visual features, high-level face representations in working memory are biased by the processing of related but task-irrelevant information.
\end{abstract}

Keywords Visual working memory $\cdot$ Distraction $\cdot$ Bias $\cdot$ Face perception

\section{Introduction}

Visual working memory (VWM) comprises the brief maintenance and manipulation of visual information. Visual perception and VWM work in tandem to construct a singular and comprehensible visual experience (Fischer \& Whitney, 2014; Kiyonaga, Scimeca, Bliss, \& Whitney, 2017). The reliance of VWM and perception on similar and overlapping neural resources (D'Esposito, 2007; D'Esposito \& Postle, 2015; Fuster, 1997; Pasternak \& Greenlee, 2005; Postle, 2006; Serences, 2016) highlights their interdependence (Awh \& Jonides, 2001; Kiyonaga \& Egner, 2013). Accordingly, previous research has shown that information retained in VWM

Significance statement Life is full of distractions, but working memory helps to protect goal-relevant information from catastrophic interference. Working memories are, however, susceptible to milder forms of interference. Here, we show that when holding a face stimulus in mind, the memory representation is systematically biased by the perception of a new face. Memory is a constructive and imperfect process, and the current study improves our understanding of how these imperfections arise.

Remington Mallett remym@utexas.edu

1 Department of Psychology, University of Texas at Austin, Austin, TX, USA

2 Westwood High School, Austin, TX, USA biases perceptual attention towards similar features in the external environment (Olivers, Peters, Houtkamp, \& Roelfsema, 2011; Soto, Hodsoll, Rotshtein, \& Humphreys, 2008), and conversely that perceptual information impacts VWM retention (Yoon, Curtis, \& D'Esposito, 2006).

Perceptual interference can impact VWM by a general disruption of performance (Allen \& Ueno, 2018; Bae \& Luck, 2018; Clapp, Rubens, \& Gazzaley, 2010; Magnussen \& Greenlee, 1992; Magnussen, Greenlee, Asplund, \& Dyrnes, 1991; Marini, Scott, Aron, \& Ester, 2017; Yoon et al., 2006). A distractor presented during the maintenance period negatively impacts performance when retaining low-level features in VWM such as color (Nemes, Parry, Whitaker, \& McKeefry, 2012; Nilsson \& Nelson, 1981), spatial frequency (Bennett \& Cortese, 1996; Magnussen et al., 1991; Nemes, Whitaker, Heron, \& McKeefry, 2011), spatial location (Marini et al., 2017), or motion (Magnussen \& Greenlee, 1992; McKeefry, Burton, \& Vakrou, 2007; Pasternak \& Zaksas, 2003). These negative consequences are often restricted to situations where the distractor and memoranda are from an overlapping feature-space (Magnussen \& Greenlee, 1992, 1999; Magnussen et al., 1991). Effects of general working memory disruption have been shown using complex stimuli such as faces and scenes (Berry, Zanto, Rutman, Clapp, \& Gazzaley, 2009; Bettencourt \& Xu, 2016; Clapp \& Gazzaley, 2012; Clapp et al., 2010; Clapp, Rubens, Sabharwal, \& Gazzaley, 2011; Feredoes, Heinen, Weiskopf, Ruff, \& Driver, 2011), and 
in some cases such consequences were dependent on targetdistractor similarity (Jha, Fabian, \& Aguirre, 2004; Jha \& Kiyonaga, 2010; Yoon et al., 2006).

When perceptual distractors and memoranda are from the same low-level feature space, and within a certain range of similarity, memory responses show an attractive bias towards the distractor. This finding has been demonstrated with color (Nemes et al., 2012), orientation (Rademaker, Bloem, De Weerd, \& Sack, 2015), spatial location (Van der Stigchel, Merten, Meeter, \& Theeuwes, 2007), and spatial frequency (Dubé, Zhou, Kahana, \& Sekuler, 2014; Huang \& Sekuler, 2010b; Nemes et al., 2011). Recently, neuroimaging evidence suggests that neural VWM representations indeed shift towards the distractor in accordance with an attractive response bias (Lorenc, Sreenivasan, Nee, Vandenbroucke, \& D'Esposito, 2018). To date, these perceptual biasing effects have not been tested using complex stimuli, which can offer insight into how these effects might apply to VWM in a more naturalistic setting.

To address this gap in the literature, we had participants remember faces under different conditions of distraction. Target and distractor faces were drawn from a continuous face space made of 80 computer-generated faces that varied continuously along the dimensions of age and sex (Lorenc, Pratte, Angeloni, \& Tong, 2014). A delayed-estimation task with a method of adjustment response was used to quantify the accuracy of memory judgments. In three experiments, participants retained a single memory item while a task-irrelevant visual distractor was presented during maintenance. The three experiments varied only in their distance between the memory target and distractor in feature space (from $45^{\circ}$ up to $135^{\circ}$ ). We predicted that responses would be biased towards the distractor, because this would be consistent with findings from similar paradigms that use low-level visual features as memoranda (e.g., Rademaker et al., 2015). The goals of this research were to relate the consequences of distraction on complex memoranda to findings for low-level stimuli, and to add to the broader consensus on the bidirectional relationship between perception and working memory.

\section{Materials and methods}

\section{Participants}

Participants were recruited from the undergraduate student body of the University of Texas at Austin through the SONA system provided by the Department of Psychology. Ninety adults participated in total (30 in each of three experiments; age range 18-22 years, 60 females). All experiments lasted approximately $60 \mathrm{~min}$, and participants were compensated with course credit for their participation. Written informed consent was obtained in a manner approved by the University of Texas Institutional Review Board.

\section{Stimuli}

Stimuli were identical for all experiments. Memory targets were selected at random from a continuous face space consisting of 80 computer-generated faces (Lorenc et al., 2014; Fig. 1). As there were 80 unique faces in the continuous space, all distances were converted to a $360^{\circ}$ space for interpretability $\left(\right.$ distance between two faces $=4.5^{\circ}$ ). The threedimensional rendered faces were gray-scaled and varied continuously along the dimensions of age and sex. Stimuli were presented on a 21.5-in. iMac using PsychoPy (Peirce, 2007). Stimuli were presented on a gray background, and all text and fixation points were white.

\section{Procedure}

The procedure was identical for all experiments except for the distance between the memory target and distractor (Fig. 2A). Participants performed a delayed-estimation task with a method of adjustment response. Each trial began with a fixation cross $\left(500 \mathrm{~ms}, 0.5^{\circ}\right.$ radius $)$ followed by a centrally presented memory target $\left(1,000 \mathrm{~ms}, 5^{\circ}\right.$ radius $)$. Participants were instructed to remember the memory target as precisely as possible over the remainder of the trial. Stimulus presentation was followed by a delay period with a central fixation dot $(3,000$ $\mathrm{ms}, 0.05^{\circ}$ radius $)$. In the middle of the delay, a task-irrelevant distractor face was presented $\left(1,000 \mathrm{~ms}, 5^{\circ}\right.$ radius $)$ in the same spatial location as the memory target. The distractor face was clockwise (50\% of trials) or counterclockwise of the memory target by approximately $45^{\circ}$ (9-11 faces, uniformly randomized) in Experiment 1, 67.5 (14-16 faces) in Experiment 2, and $135^{\circ}$ (29-31 faces) in Experiment 3. During training, participants were instructed to ignore the task-irrelevant distractor face while maintaining fixation. They were not informed of any relationship between the distractor and the memory target. Following the delay, participants selected the memory target from a continuous wheel using a computer mouse ( $\leq 30 \mathrm{~s})$. The probe stage began with the computer cursor positioned centrally, and a dark gray wheel was presented $\left(6.5^{\circ}\right.$ radius, $3^{\circ}$ thickness $)$ surrounding a face that morphed continuously (across all 80 faces of the face space) as the cursor moved around the wheel. The orientation of the face space was rotated randomly along the wheel every trial, and a face was not presented centrally until the cursor made contact with the wheel. Following response via mouse click, participants were provided feedback with a green indicator of the correct location of the memory target on the probe wheel (500 ms). Trials were separated with a 1,000-ms blank intertrial-interval (ITI). Each participant completed a single training run and then eight experimental runs of 24 trials each. 


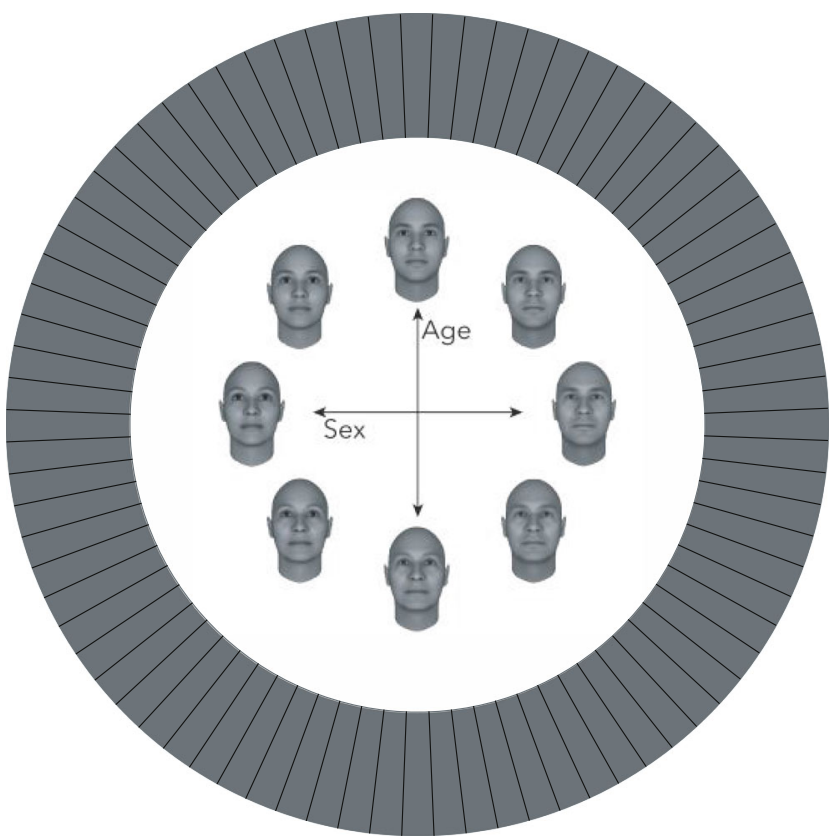

Fig. 1 Stimulus face space. Stimuli were 80 computer-generated faces that varied along dimensions of age and sex. Eighty slices around the wheel provide visualization of how much circular space each face occupied, and were not present during the experiment

\section{Analysis}

Each trial's error was calculated as the difference in degrees in the continuous face space between the response and the target. To quantify bias for each trial, we extracted the absolute response error in degrees, and assigned it a positive sign if the error was in the same direction as the distractor, and a negative sign otherwise. Therefore, a positive value indicates an attractive bias (i.e., a response towards the distractor), and a negative value represents a repulsive bias (i.e., a response away from the distractor). In all experiments, this bias metric inherently collapses across clockwise and counterclockwise distractors. When evaluating whether a response bias was present, we performed a one-sample t-test against zero, where each participant contributed a single bias metric. To compare absolute response errors and biases across experiments, we performed between-subjects ANOVAs using the Pingouin Python package (Vallat, 2018). All statistical tests were twotailed, and effect size $d_{z}$ was calculated for all one-sample tests (Cumming, 2013). For each experiment, we removed outliers whose response biases across all trials were beyond 1.5 standard deviations from the mean (Exp. 1: $N=2$, Exp. 2: $N=5$, Exp. 3: $N=4$ ) to account for "swapped' responses where participants might have responded to the probe by selecting the distractor. Trials with no response in the time provided were removed (Exp. 1: five trials, Exp. 2: two trials, Exp. 3: no trials). All in-text descriptive statistics are reported as mean and standard deviation.

\section{Results}

Mean absolute response error was similar across experiments $\left(F_{(2,76)}=0.6, p=0.55\right)$ with $29.3 \pm 9^{\circ}$ in Experiment $1,28.4 \pm 8^{\circ}$ in Experiment 2, and $31.1 \pm 11^{\circ}$ in Experiment 3 (Fig. 2B). In Experiment 1, average response bias was reliably positive $\left(M=1.34 \pm 3.2^{\circ}, t_{(27)}=2.23, p=0.034, d_{z}=0.42\right)$, reflecting a tendency of memory responses to be attracted towards the perceptual distractor (Fig. 3). This effect was replicated in

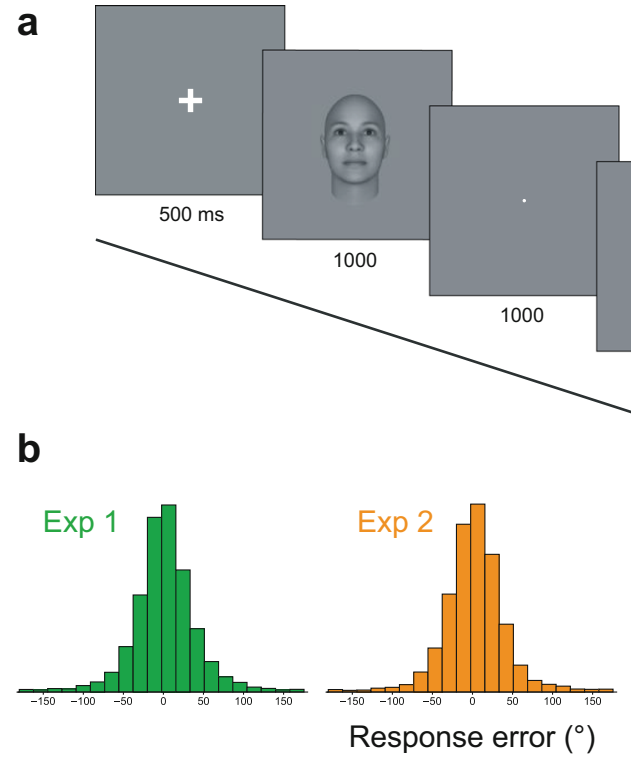

Fig. 2 (A) Experiment 1 task design. Participants encoded a single memory target and responded after a distractor-filled delay. Experiments differed only in the distance between target and distractor.

\section{Distractor}

$\sim 45^{\circ}$ away in Exp 1

$\sim 67.5^{\circ}$ away in Exp 2

$\sim 135^{\circ}$ away in Exp 3

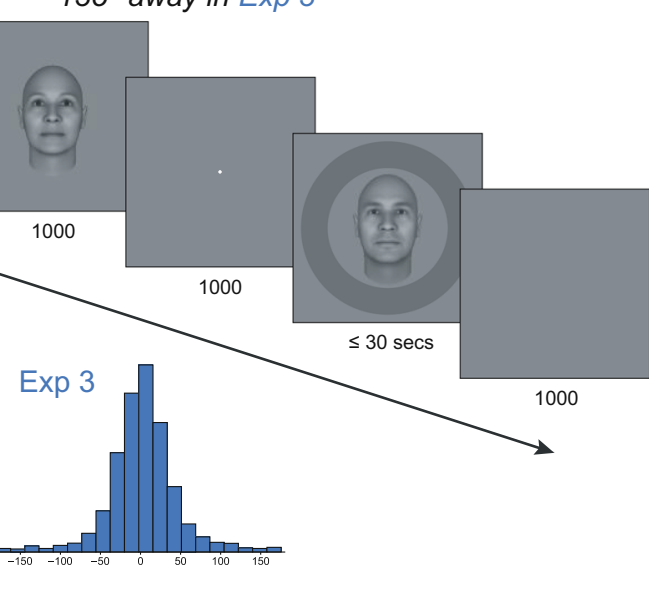

(B) Response error distributions. Response errors were normally distributed around the target and absolute response error was similar across all experiments 
Experiment 2 in which there was an increase from $45^{\circ}$ to $67.5^{\circ}$ in the distance between memory target and distractor $(M=1.62$ $\left.\pm 2.5^{\circ} ; t_{(24)}=3.31, p=0.003, d_{z}=0.66\right)$. Similarly, the effect was present when the target-distractor distance increased to $135^{\circ}$ $\left(M=1.71 \pm 2.1^{\circ} ; t_{(25)}=4.12, p<0.001, d_{z}=0.81\right)$. While effect size increased with distractor distance, the magnitude of the bias effect did not differ across experiments $\left(F_{(2,76)}=0.1\right.$, $p=0.87$ ).

\section{Discussion}

In three experiments, we tested the hypothesis that perceptual distraction presented during the delay of a visual working memory (VWM) task biases memory for faces. We found this to be the case across all experiments (total $N=90$ ). Our finding that working memories of complex stimuli are biased towards the perceptual distractor is consistent with previous results with low-level features as memoranda (Dubé et al., 2014; Huang \& Sekuler, 2010a; Nemes et al., 2012, 2011; Rademaker et al., 2015; Van der Stigchel et al., 2007). Previous serial dependence research suggests that face perception is influenced by recently viewed faces (Liberman, Fischer, \& Whitney, 2014; Taubert, Alais, \& Burr, 2016). Here we show the reverse, that perceived faces impact recently encoded working memories of faces.

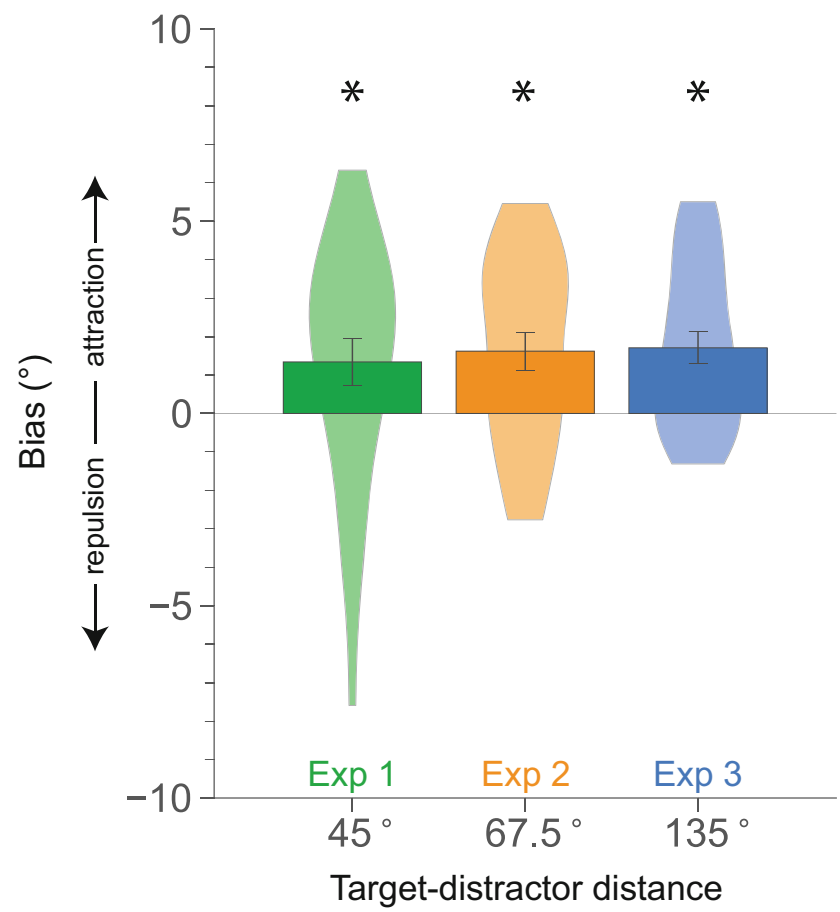

Fig. 3 Bias results from each experiment. Responses were similarly biased towards perceptual distractors across all experiments. The bias metric represents combined bias across all trials within each experiment. (error bars represent SEM; violin plots show density of individual participant data points; ${ }^{*} \mathrm{p}<.05$ )
Our findings of VWM response bias towards a perceptual distractor that is matched in feature space replicate previous findings that used color (Nemes et al., 2012), orientation (Rademaker et al., 2015), spatial location (Van der Stigchel et al., 2007), or spatial frequency (Dubé et al., 2014; Huang \& Sekuler, 2010b; Nemes et al., 2011). Thus, our finding that this effect generalizes to complex stimuli like faces suggests that these stimuli share similar representational properties as basic features in VWM. It is possible that our observed bias resulted from low-level features that varied across the face stimulus set. However, this is unlikely given that facial recognition is frequently characterized as a holistic process, in that there is a tendency to perceive faces as an integrated whole rather than a composite of individual features (Farah, Wilson, Drain, \& Tanaka, 1998; Taubert, Apthorp, Aagten-Murphy, \& Alais, 2011). Regardless of whether the attractive bias we found across all experiments resulted from basic features or complex representations, the influence of perceived faces on memorized faces is consistent with the sensory recruitment account of VWM where perceptual resources are recruited for VWM storage (D’Esposito, 2007; D'Esposito \& Postle, 2015; Fuster, 1997; Pasternak \& Greenlee, 2005; Postle, 2006; Serences, 2016).

We found no effect of target-distractor distance on the magnitude or direction of working memory biases. Previous work has shown that increasing target-distractor distance increased memory bias (Rademaker et al., 2015); however, this was tested within target-distractor distances all below $45^{\circ}$, which was the lowest target-distractor distance in the current study. In previous work investigating the biasing effects between multiple VWM representations, the attractive/repulsive biasing effects are largely dependent on target-distractor distance (Bae \& Luck, 2017; Myers, Chekroud, Stokes, \& Nobre, 2018). Biasing complex stimuli such as faces might be weaker than the biasing of low-level visual features. Furthermore, the "distance" between targets and distractors might be more ambiguous because these stimuli vary across more than one dimension, unlike the typical unidimensional and continuous feature space of low-level stimuli. Additionally, some categorical and/or verbal recoding (Lewis-Peacock, Drysdale, \& Postle, 2015) of the remembered faces might have occurred (Smyth, Hay, Hitch, \& Horton, 2005), possibly preventing the subtle differences in bias as a function of distance. Notably, the similarity in bias across target-distractor distances provides further support that our results are unlikely to have resulted from "swapped" representations of target and distractor.

Our current design is unable to rule out the possibility of categorical recoding along the dimensions of age and sex (e.g., "old-ness" or "male-ness"). Indeed, this is also the case for similar experiments using low-level features. Even low-level features are recoded into categorical representations during working memory tasks (Bae, Olkkonen, Allred, \& Flombaum, 2015; Hardman, Vergauwe, \& Ricker, 2017). Furthermore, in another 
situation where memory and perception interact, categorical verbal information in working memory can bias visual attention (Mannan, Kennard, Potter, Pan, \& Soto, 2010; Soto \& Humphreys, 2007; Soto, Rotshtein, Hodsoll, Mevorach, \& Humphreys, 2012). Together, this suggests that if individual faces were recoded into categorical and/or verbal representations, we might still have detected these biasing effects. Note that participants were never explicitly informed about the two dimensions of age and sex that differed within the face space, which makes categorical recoding less likely. Future work using either neuroimaging or tasks that prevent verbal rehearsal (e.g., articulatory suppression) might help to determine how recoding influences biasing.

Face perception - like low-level features - is susceptible to visual adaptation, or "after-effects" (Jeffery \& Rhodes, 2011; Strobach \& Carbon, 2013; Webster \& MacLeod, 2011). Aftereffects alter perception of images based on recent encoding of related material. As with low-level features, perception of faces can influence processing such that perception is biased away from the initially encoded face (e.g., adaptation to a male face resulting in a female bias; Webster, Kaping, Mizokami, \& Duhamel, 2004). These effects have been found in face perception for both age (Schweinberger et al., 2010) and sex (Webster et al., 2004). After encoding the target face in the current experiments, perception of the distractor face might have been biased away from the target as a result of face-adaptation effects. Such a perceptual effect (either attraction or repulsion) might have influenced our results, but because the attractive biases we found were markedly smaller than the actual distance between target and distractor, we are unable to determine exactly how the distractor face was perceived.

Neuroimaging work has proposed a variety of neural mechanisms supporting maintenance during distraction periods of a VWM task. Proposals range across active maintenance in early visual (Lorenc et al., 2018) or parietal (Bettencourt \& Xu, 2016; Lorenc et al., 2018) regions, activity-silent mechanisms (LewisPeacock, Drysdale, Oberauer, \& Postle, 2012), connectivity between frontal and occipital regions (Clapp et al., 2010), or systematically modulated activity patterns (Derrfuss, Ekman, Hanke, Tittgemeyer, \& Fiebach, 2017; van Loon, Olmos-Solis, Fahrenfort, \& Olivers, 2018). Recently, Lorenc et al. (2018) showed that a perceptual distractor presented during a memory delay exerted an attractive bias on both behavioral responses and the neural representation in early visual areas. This suggests that the attractive biasing effects that arise in behavior correspond with active neural maintenance, yet the influence of neural overlap between target and distractor representations is still an open question.

As a final note, our use of faces as memoranda aids in the ecological validity of these results (Leopold \& Rhodes, 2010). The biases demonstrated here in VWM might be applicable to important issues such as eyewitness testimony. Eyewitness testimony - primarily studied in the context of episodic memory (Chan, Thomas, \& Bulevich, 2009; Thomas, Bulevich, \& Chan, 2010) - is vulnerable to interference and misinformation (Butler \& Loftus, 2018; Echterhoff, Hirst, \& Hussy, 2005), specifically during suspect lineups. Suspect lineups require witnesses to choose a target face from a series of simultaneously or sequentially presented faces with similar critical features (Huff \& Umanath, 2018). Our findings of perceptual distraction suggest that working memory may play a role in these decisions and impact the reliability of eyewitness testimony.

In summary, the current study contributes to a growing literature consensus that VWM representations are biased by distractors that vary along a goal-relevant feature dimension, and more generally that VWM and perception systematically influence each other. Our findings using a stimulus set that varies along complex feature dimensions suggests that the biasing effects of distractors on memories is a general characteristic of VWM that affects representations beyond those of low-level features.

Acknowledgements The authors thank Elizabeth Lorenc for providing the face stimulus set and for helpful discussions on this project. We also thank Sara Vargas, Scott Lacritz, and Imran Khan for contributing to data collection.

Funding disclosure This work was supported by the National Eye Institute of the National Institutes of Health under Award Number R01EY028746 (JLP).

Open practices statement All data, code, and stimuli are available on the OSF project site at https://osf.io/8zsrx/. None of the experiments were preregistered.

Author contributions RM, AM, and JLP conceived and designed the study and wrote the paper. RM and AM collected and analyzed data.

\section{Compliance with ethical standards}

Conflict of interest statement The authors declare no potential conflicts of interest.

\section{References}

Allen, R. J., \& Ueno, T. (2018). Multiple high-reward items can be prioritized in working memory but with greater vulnerability to interference. Attention, Perception, \& Psychophysics, 80(7), 1731-1743. doi:https://doi.org/10.3758/s13414-018-1543-6

Awh, E., \& Jonides, J. (2001). Overlapping mechanisms of attention and spatial working memory. Trends in Cognitive Sciences, 5(3), 119 126. doi:https://doi.org/10.1016/S1364-6613(00)01593-X

Bae, G.-Y., \& Luck, S. J. (2017). Interactions between visual working memory representations. Attention, Perception, \& Psychophysics, 79(8), 2376-2395. doi:https://doi.org/10.3758/s13414-017-1404-8

Bae, G.-Y., \& Luck, S. J. (2018). What happens to an individual visual working memory representation when it is interrupted? British Journal of Psychology. doi:https://doi.org/10.1111/bjop.12339

Bae, G.-Y., Olkkonen, M., Allred, S. R., \& Flombaum, J. I. (2015). Why some colors appear more memorable than others: A model 
combining categories and particulars in color working memory. Journal of Experimental Psychology: General, 144(4), 744-763. doi:https://doi.org/10.1037/xge0000076

Bennett, P. J., \& Cortese, F. (1996). Masking of spatial frequency in visual memory depends on distal, not retinal, frequency. Vision Research, 36(2), 233-238. doi:https://doi.org/10.1016/0042-6989(95)00085-E

Berry, A. S., Zanto, T. P., Rutman, A. M., Clapp, W. C., \& Gazzaley, A. (2009). Practice-Related Improvement in Working Memory is Modulated by Changes in Processing External Interference. Journal of Neurophysiology, 102(3), 1779-1789. doi:https://doi. org/10.1152/jn.00179.2009

Bettencourt, K. C., \& Xu, Y. (2016). Decoding the content of visual shortterm memory under distraction in occipital and parietal areas. Nature Neuroscience, 19(1), 150-157. doi:https://doi.org/10.1038/nn.4174

Butler, B. J., \& Loftus, E. F. (2018). Discrepancy detection in the retrieval-enhanced suggestibility paradigm. Memory, 26(4), 483492. doi:https://doi.org/10.1080/09658211.2017.1371193

Chan, J. C. K., Thomas, A. K., \& Bulevich, J. B. (2009). Recalling a Witnessed Event Increases Eyewitness Suggestibility: The Reversed Testing Effect. Psychological Science, 20(1), 66-73. doi:https://doi. org/10.1111/j.1467-9280.2008.02245.x

Clapp, W. C., \& Gazzaley, A. (2012). Distinct mechanisms for the impact of distraction and interruption on working memory in aging. Neurobiology of Aging, 33(1), 134-148. doi:https://doi.org/10. 1016/j.neurobiolaging.2010.01.012

Clapp, W. C., Rubens, M. T., \& Gazzaley, A. (2010). Mechanisms of Working Memory Disruption by External Interference. Cerebral Cortex, 20(4), 859-872. doi:https://doi.org/10.1093/cercor/bhp150

Clapp, W. C., Rubens, M. T., Sabharwal, J., \& Gazzaley, A. (2011). Deficit in switching between functional brain networks underlies the impact of multitasking on working memory in older adults. Proceedings of the National Academy of Sciences, 108(17), 7212 7217. doi:https://doi.org/10.1073/pnas.1015297108

Cumming, G. (2013). Understanding The New Statistics: Effect Sizes, Confidence Intervals, and Meta-Analysis. doi:https://doi.org/10. 4324/9780203807002

Derrfuss, J., Ekman, M., Hanke, M., Tittgemeyer, M., \& Fiebach, C. J. (2017). Distractor-resistant Short-Term Memory Is Supported by Transient Changes in Neural Stimulus Representations. Journal of Cognitive Neuroscience, 29(9), 1547-1565. doi:https://doi.org/10. 1162/jocn_a_01141

D'Esposito, M. (2007). From cognitive to neural models of working memory. Philosophical Transactions of the Royal Society of London B: Biological Sciences, 362(1481), 761-772. doi:https:// doi.org/10.1098/rstb.2007.2086

D'Esposito, M., \& Postle, B. R. (2015). The Cognitive Neuroscience of Working Memory. Annual Review of Psychology, 66(1), 115-142. doi:https://doi.org/10.1146/annurev-psych-010814-015031

Dubé, C., Zhou, F., Kahana, M. J., \& Sekuler, R. (2014). Similarity-based distortion of visual short-term memory is due to perceptual averaging. Vision Research, 96, 8-16. doi:https://doi.org/10.1016/j.visres. 2013.12.016

Echterhoff, G., Hirst, W., \& Hussy, W. (2005). How eyewitnesses resist misinformation: Social postwarnings and the monitoring of memory characteristics. Memory \& Cognition, 33(5), 770-782. doi:https:// doi.org/10.3758/BF03193073

Farah, M. J., Wilson, K. D., Drain, M., \& Tanaka, J. N. (1998). What is "special" about face perception? Psychological Review, 105(3), 482-498. doi:https://doi.org/10.1037/0033-295X.105.3.482

Feredoes, E., Heinen, K., Weiskopf, N., Ruff, C., \& Driver, J. (2011). Causal evidence for frontal involvement in memory target maintenance by posterior brain areas during distracter interference of visual working memory. Proceedings of the National Academy of Sciences, 108(42), 17510-17515. doi:https://doi.org/10.1073/pnas. 1106439108
Fischer, J., \& Whitney, D. (2014). Serial dependence in visual perception. Nature Neuroscience, 17(5), 738-743. doi:https://doi.org/10.1038/ nn.3689

Fuster, J. M. (1997). Network memory. Trends in Neurosciences, 20(10), 451-459. doi:https://doi.org/10.1016/S0166-2236(97)01128-4

Hardman, K. O., Vergauwe, E., \& Ricker, T. J. (2017). Categorical working memory representations are used in delayed estimation of continuous colors. Journal of Experimental Psychology: Human Perception and Performance, 43(1), 30-54. doi:https://doi.org/10. 1037/xhp0000290

Huang, J., \& Sekuler, R. (2010a). Attention Protects the Fidelity of Visual Memory: Behavioral and Electrophysiological Evidence. Journal of Neuroscience, 30(40), 13461-13471. doi:https://doi.org/10.1523/ JNEUROSCI.2560-10.2010

Huang, J., \& Sekuler, R. (2010b). Distortions in recall from visual memory: Two classes of attractors at work. Journal of Vision, 10(2), 24 24. doi:https://doi.org/10.1167/10.2.24

Huff, M. J., \& Umanath, S. (2018). Evaluating suggestibility to additive and contradictory misinformation following explicit error detection in younger and older adults. Journal of Experimental Psychology: Applied, 24(2), 180-195. doi:https://doi.org/10.1037/xap0000138

Jeffery, L., \& Rhodes, G. (2011). Insights into the development of face recognition mechanisms revealed by face aftereffects. British Journal of Psychology, 102(4), 799-815. doi:https://doi.org/10. $1111 / j .2044-8295.2011 .02066 . x$

Jha, A. P., Fabian, S. A., \& Aguirre, G. K. (2004). The role of prefrontal cortex in resolving distractor interference. Cognitive, Affective, \& Behavioral Neuroscience, 4(4), 517-527. doi:https://doi.org/10. 3758/CABN.4.4.517

Jha, A. P., \& Kiyonaga, A. (2010). Working-memory-triggered dynamic adjustments in cognitive control. Journal of Experimental Psychology: Learning, Memory, and Cognition, 36(4), 10361042. doi:https://doi.org/10.1037/a0019337

Kiyonaga, A., \& Egner, T. (2013). Working memory as internal attention: Toward an integrative account of internal and external selection processes. Psychonomic Bulletin \& Review, 20(2), 228-242. doi: https://doi.org/10.3758/s13423-012-0359-y

Kiyonaga, A., Scimeca, J. M., Bliss, D. P., \& Whitney, D. (2017). Serial Dependence across Perception, Attention, and Memory. Trends in Cognitive Sciences, 21(7), 493-497. doi:https://doi.org/10.1016/j. tics.2017.04.011

Leopold, D. A., \& Rhodes, G. (2010). A comparative view of face perception. Journal of Comparative Psychology, 124(3), 233-251. doi: https://doi.org/10.1037/a0019460

Lewis-Peacock, J. A., Drysdale, A. T., Oberauer, K., \& Postle, B. R. (2012). Neural Evidence for a Distinction between Short-term Memory and the Focus of Attention. Journal of Cognitive Neuroscience, 24(1), 61-79. doi:https://doi.org/10.1162/jocn_a 00140

Lewis-Peacock, J. A., Drysdale, A. T., \& Postle, B. R. (2015). Neural Evidence for the Flexible Control of Mental Representations. Cerebral Cortex, 25(10), 3303-3313. doi:https://doi.org/10.1093/ cercor/bhu130

Liberman, A., Fischer, J., \& Whitney, D. (2014). Serial Dependence in the Perception of Faces. Current Biology, 24(21), 2569-2574. doi: https://doi.org/10.1016/j.cub.2014.09.025

Lorenc, E. S., Pratte, M. S., Angeloni, C. F., \& Tong, F. (2014). Expertise for upright faces improves the precision but not the capacity of visual working memory. Attention, Perception, \& Psychophysics, 76(7), 1975-1984. doi:https://doi.org/10.3758/s13414-014-0653-Z

Lorenc, E. S., Sreenivasan, K. K., Nee, D. E., Vandenbroucke, A. R. E., \& D’Esposito, M. (2018). Flexible coding of visual working memory representations during distraction. Journal of Neuroscience, 38(23), 5267-5276. doi:https://doi.org/10.1523/JNEUROSCI.3061-17. 2018 
Magnussen, S., \& Greenlee, M. W. (1992). Retention and disruption of motion information in visual short-term memory. Journal of Experimental Psychology: Learning, Memory, and Cognition, 18(1), 151-156. doi:https://doi.org/10.1037/0278-7393.18.1.151

Magnussen, S., \& Greenlee, M. W. (1999). The psychophysics of perceptual memory. Psychological Research, 62(2), 81-92. doi:https:// doi.org/10.1007/s004260050043

Magnussen, S., Greenlee, M. W., Asplund, R., \& Dyrnes, S. (1991). Stimulus-specific mechanisms of visual short-term memory. Vision Research, 31(7), 1213-1219. doi:https://doi.org/10.1016/00426989(91)90046-8

Mannan, S. K., Kennard, C., Potter, D., Pan, Y., \& Soto, D. (2010). Early oculomotor capture by new onsets driven by the contents of working memory. Vision Research, 50(16), 1590-1597. doi:https://doi.org/ 10.1016/j.visres.2010.05.015

Marini, F., Scott, J., Aron, A. R., \& Ester, E. F. (2017). Task-irrelevant distractors in the delay period interfere selectively with visual shortterm memory for spatial locations. Attention, Perception, \& Psychophysics, 79(5), 1384-1392. doi:https://doi.org/10.3758/ s13414-017-1320-y

McKeefry, D. J., Burton, M. P., \& Vakrou, C. (2007). Speed selectivity in visual short term memory for motion. Vision Research, 47(18), 2418-2425. doi:https://doi.org/10.1016/j.visres.2007.05.011

Myers, N. E., Chekroud, S. R., Stokes, M. G., \& Nobre, A. C. (2018). Benefits of flexible prioritization in working memory can arise without costs. Journal of Experimental Psychology: Human Perception and Performance, 44(3), 398-411. doi:https://doi.org/10.1037/ xhp0000449

Nemes, V. A., Parry, N. R. A., Whitaker, D., \& McKeefry, D. J. (2012). The retention and disruption of color information in human shortterm visual memory. Journal of Vision, 12(1), 26-26. doi:https://doi. org/10.1167/12.1.26

Nemes, V. A., Whitaker, D., Heron, J., \& McKeefry, D. J. (2011). Multiple spatial frequency channels in human visual perceptual memory. Vision Research, 51(23), 2331-2339. doi:https://doi.org/ 10.1016/j.visres.2011.09.003

Nilsson, T. H., \& Nelson, T. M. (1981). Delayed monochromatic hue matches indicate characteristics of visual memory. Journal of Experimental Psychology: Human Perception and Performance, 7(1), 141-150. doi:https://doi.org/10.1037/0096-1523.7.1.141

Olivers, C. N. L., Peters, J., Houtkamp, R., \& Roelfsema, P. R. (2011). Different states in visual working memory: When it guides attention and when it does not. Trends in Cognitive Sciences, 15(7), 327-334. doi:https://doi.org/10.1016/j.tics.2011.05.004

Pasternak, T., \& Greenlee, M. W. (2005). Working memory in primate sensory systems. Nature Reviews Neuroscience, 6(2), 97-107. doi: https://doi.org/10.1038/nrn1603

Pasternak, T., \& Zaksas, D. (2003). Stimulus Specificity and Temporal Dynamics of Working Memory for Visual Motion. Journal of Neurophysiology, 90(4), 2757-2762. doi:https://doi.org/10.1152/jn. 00422.2003

Peirce, J. W. (2007). PsychoPy-Psychophysics software in Python. Journal of Neuroscience Methods, 162(1), 8-13. doi:https://doi. org/10.1016/j.jneumeth.2006.11.017

Postle, B. R. (2006). Working memory as an emergent property of the mind and brain. Neuroscience, 139(1), 23-38. doi:https://doi.org/10. 1016/j.neuroscience.2005.06.005

Rademaker, R. L., Bloem, I. M., De Weerd, P., \& Sack, A. T. (2015). The impact of interference on short-term memory for visual orientation. Journal of Experimental Psychology: Human Perception and Performance, 41(6), 1650-1665. doi:https://doi.org/10.1037/ xhp0000110

Schweinberger, S. R., Zäske, R., Walther, C., Golle, J., Kovács, G., \& Wiese, H. (2010). Young without plastic surgery: Perceptual adaptation to the age of female and male faces. Vision Research, 50(23), 2570-2576. doi:https://doi.org/10.1016/j.visres.2010.08. 017

Serences, J. T. (2016). Neural mechanisms of information storage in visual short-term memory. Vision Research, 128(Supplement C), 53-67. doi:https://doi.org/10.1016/j.visres.2016.09.010

Smyth, M. M., Hay, D. C., Hitch, G. J., \& Horton, N. J. (2005). Serial position memory in the visual - spatial domain: Reconstructing sequences of unfamiliar faces. The Quarterly Journal of Experimental Psychology, 58A(5), 909-930. doi:https://doi.org/10.1080/ 02724980443000412

Soto, D., Hodsoll, J., Rotshtein, P., \& Humphreys, G. W. (2008). Automatic guidance of attention from working memory. Trends in Cognitive Sciences, 12(9), 342-348. doi:https://doi.org/10.1016/j. tics.2008.05.007

Soto, D., \& Humphreys, G. W. (2007). Automatic guidance of visual attention from verbal working memory. Journal of Experimental Psychology Human Perception and Performance, 33(3), 730-737. doi:https://doi.org/10.1037/0096-1523.33.3.730

Soto, D., Rotshtein, P., Hodsoll, J., Mevorach, C., \& Humphreys, G. W. (2012). Common and distinct neural regions for the guidance of selection by visuoverbal information held in memory: Converging evidence from fMRI and rTMS. Human Brain Mapping, 33(1), 105-120. doi:https://doi.org/10.1002/hbm.21196

Strobach, T., \& Carbon, C.-C. (2013). Face Adaptation Effects: Reviewing the Impact of Adapting Information, Time, and Transfer. Frontiers in Psychology, 4. doi:https://doi.org/10.3389/ fpsyg.2013.00318

Taubert, J., Alais, D., \& Burr, D. (2016). Different coding strategies for the perception of stable and changeable facial attributes. Scientific Reports, 6, 32239. doi:https://doi.org/10.1038/srep32239

Taubert, J., Apthorp, D., Aagten-Murphy, D., \& Alais, D. (2011). The role of holistic processing in face perception: Evidence from the face inversion effect. Vision Research, 51(11), 1273-1278. doi:https:// doi.org/10.1016/j.visres.2011.04.002

Thomas, A. K., Bulevich, J. B., \& Chan, J. C. K. (2010). Testing promotes eyewitness accuracy with a warning: Implications for retrieval enhanced suggestibility. Journal of Memory and Language, 63(2), 149-157. doi:https://doi.org/10.1016/j.jml.2010.04.004

Vallat, R. (2018). Pingouin: Statistics in Python. Journal of Open Source Software, 3(31), 1026. doi:10.21105/joss.01026

Van der Stigchel, S., Merten, H., Meeter, M., \& Theeuwes, J. (2007). The effects of a task-irrelevant visual event on spatial working memory. Psychonomic Bulletin \& Review, 14(6), 1066-1071. doi:https://doi. org/10.3758/BF03193092

van Loon, A. M., Olmos-Solis, K., Fahrenfort, J. J., \& Olivers, C. N. L. (2018). Current and future goals are represented in opposite patterns in object-selective cortex. ELife, 7, e38677. doi:https://doi.org/10. 7554/eLife.38677

Webster, M. A., Kaping, D., Mizokami, Y., \& Duhamel, P. (2004). Adaptation to natural facial categories. Nature, 428(6982), $557-$ 561. doi:https://doi.org/10.1038/nature02420

Webster, M. A., \& MacLeod, D. I. A. (2011). Visual adaptation and face perception. Philosophical Transactions of the Royal Society B: Biological Sciences, 366(1571), 1702-1725. doi:https://doi.org/10. 1098/rstb.2010.0360

Yoon, J. H., Curtis, C. E., \& D’Esposito, M. (2006). Differential effects of distraction during working memory on delay-period activity in the prefrontal cortex and the visual association cortex. NeuroImage, 29(4), 1117-1126. doi:https://doi.org/10.1016/j.neuroimage.2005. 08.024

Publisher's note Springer Nature remains neutral with regard to jurisdictional claims in published maps and institutional affiliations. 